\title{
ZEB1 limits adenoviral infectability by transcriptionally repressing the Coxsackie virus and Adenovirus Receptor
}

\author{
Markus D Lacher ${ }^{1,3}$, Marisa Shiina ${ }^{1}$, Peter Chang ${ }^{1,4}$, Debora Keller ${ }^{1,5}$, Maarit I Tiirikainen ${ }^{1,6}$ and W Michael Korn ${ }^{1,2,7^{*}}$
}

\begin{abstract}
Background: We have previously reported that RAS-MEK (Cancer Res. 2003 May 1;63(9):2088-95) and TGF- $\beta$ (Cancer Res. 2006 Feb 1;66(3):1648-57) signaling negatively regulate coxsackie virus and adenovirus receptor (CAR) cellsurface expression and adenovirus uptake. In the case of TGF- $\beta$, down-regulation of CAR occurred in context of epithelial-to-mesenchymal transition (EMT), a process associated with transcriptional repression of E-cadherin by, for instance, the E2 box-binding factors Snail, Slug, SIP1 or ZEB1. While EMT is crucial in embryonic development, it has been proposed to contribute to the formation of invasive and metastatic carcinomas by reducing cell-cell contacts and increasing cell migration.
\end{abstract}

Results: Here, we show that ZEB1 represses CAR expression in both PANC-1 (pancreatic) and MDA-MB-231 (breast) human cancer cells. We demonstrate that ZEB1 physically associates with at least one of two closely spaced and conserved E2 boxes within the minimal CAR promoter here defined as genomic region -291 to -1 relative to the translational start ATG. In agreement with ZEB1's established role as a negative regulator of the epithelial phenotype, silencing its expression in MDA-MB-231 cells induced a partial Mesenchymal-to-Epithelial Transition (MET) characterized by increased levels of E-cadherin and CAR, and decreased expression of fibronectin. Conversely, knockdown of ZEB1 in PANC-1 cells antagonized both the TGF- $\beta$-induced down-regulation of E-cadherin and CAR and the reduction of adenovirus uptake. Interestingly, even though ZEB1 clearly contributes to the TGF- $\beta$-induced mesenchymal phenotype of PANC-1 cells, TGF- $\beta$ did not seem to affect ZEB1's protein levels or subcellular localization. These findings suggest that TGF- $\beta$ may inhibit CAR expression by regulating factor(s) that cooperate with ZEB1 to repress the CAR promoter, rather than by regulating ZEB1 expression levels. In addition to the negative E2 box-mediated regulation the minimal CAR promoter is positively regulated through conserved ETS and CRE elements.

Conclusions: This report provides evidence that inhibition of ZEB1 may improve adenovirus uptake of cancer cells that have undergone EMT and for which ZEB1 is necessary to maintain the mesenchymal phenotype. Targeting of ZEB1 may reverse some aspects of EMT including the down-regulation of CAR.

Keywords: ZEB1, EMT, MET, TGF- $\beta$, adenovirus, cancer

\footnotetext{
* Correspondence: michael.korn@ucsf.edu

'Dept. of Medicine, Division of Gastroenterology, University of California, San

Francisco, CA, USA

Full list of author information is available at the end of the article
} 


\section{Background}

The coxsackie virus and adenovirus receptor (CAR), encoded by the CXADR gene, is localized at the apicolateral/basolateral surface of polarized epithelial cells and serves as a component of tight junctions, thus participating in the sealing of the epithelial layer. In addition to its basolateral localization, recently, an apically localized isoform $\left(\mathrm{CAR}^{\mathrm{Ex} 8}\right)$ was described which may be responsible for initiation of respiratory adenoviral infections [1]. Furthermore, CAR regulates cardiac conductance, as demonstrated in a mouse model in which heart-specific inducible CAR knockout resulted in impaired electrical conductance between atrium and ventricle [2].

CAR is the primary receptor for adenovirus serotypes 2 and 5 [3] and thus a likely determining factor for the efficacy of adenovirus-based cancer therapy. A number of mechanisms by which CAR expression is regulated have been described, but our understanding of how to manipulate CAR expression levels in cancer is incomplete [4-11]. Learning the molecular machinery regulating CAR expression could set the stage for pharmacological interventions aimed at achieving high cell surface CAR levels to maximize virus uptake.

We previously identified RAS-MEK [5] and TGF- $\beta$ signaling [9] as negative regulators of CAR expression in cancer cell lines. Down-regulation of CAR through TGF- $\beta$ occurred in the context of epithelial-to-mesenchymal transition (EMT), a process that refers to the formation of mesenchymal cells from epithelial cells without the involvement of stem cells. During EMT, both tight junctions at apicolateral surfaces containing CAR, and more basolateral adherens junctions containing E-cadherin are disrupted, and cells acquire a motile phenotype. EMT has evolved as an important developmental program. However, inappropriate activation is linked to pathological conditions such as fibrosis and cancer [12]. In the case of cancer, EMT may contribute to the formation of invasive and metastatic carcinomas by reducing cell-cell contacts and increasing cell migration [13-15]. Additionally, the EMT-associated reduction of cell surface CAR likely makes advanced malignancies with already poor prognosis less responsive to treatment with oncolytic adenoviruses [5,9].

One of the most prominent inducers of EMT is TGF$\beta$. It is postulated that TGF- $\beta$ inhibits cell cycle progression, but alters the tumor microenvironment, promotes EMT, immunosuppression and angiogenesis in advanced malignancies, thus playing both tumor suppressive and oncogenic roles during multistage carcinogenesis [16-22]. The switch from tumor suppressor to oncogene may occur upon loss of the cytostatic arm of the TGF- $\beta$ pathway, for instance through genetic inactivation of tumor suppressive TGF- $\beta$ downstream effectors such as p15INK4b, a cyclin-dependent kinase (CDK) inhibitor [20].

Mechanisms underlying TGF- $\beta$-induced EMT involve E2 box-binding transcriptional repressors, in particular Snail (SNAI1), Slug (SNAI2), SIP1 (ZEB2) and ZEB1 $(Z E B 1)$. These repressors target genes whose protein products are instrumental for the integrity of the epithelial phenotype [23-25]. Interestingly, in addition to regulating protein-encoding genes, ZEB1 and SIP1 are both targets and negative regulators of microRNA-200 (miR200) family members. Depending on whether an extracellular stimulus up-regulates ZEB1 or SIP1, or raises miR-200 levels, the resulting positive feedback loop may stabilize either a mesenchymal (elevated ZEB1 and/or SIP1 activity) or an epithelial (increased miR-200 levels) state [26-28]. Furthermore, consistent with the proposed contribution of EMT to cancer progression, expression of E2 box-binding repressors has been observed in several malignancies [25,29-32].

The aim of this study was to examine the mechanism by which TGF- $\beta$ down-regulates CAR. By investigating how RAS-MEK [5] and TGF- $\beta$ signaling [9] impact on CAR expression, we noticed similar expression patterns for CAR and E-cadherin, suggesting common underlying regulatory mechanisms. We show here that for the regulation through TGF- $\beta$ this is indeed the case. Both CAR and E-cadherin promoters are structurally conserved around two closely spaced E2 boxes. We provide evidence that ZEB1, which has previously been reported to repress E-cadherin expression [25,33-36], also down-regulates CAR. This study, in combination with the work of others $[26,27,34,36]$, identifies ZEB1 as a potential therapeutic target for strategies aimed at improving uptake of therapeutic adenoviruses and preventing or reversing cancer-associated EMT processes while leaving the tumor suppressive functions of TGF- $\beta$ unaffected. As our work was in progress, a report was published demonstrating that TGF- $\beta$ may repress the mouse CAR promoter through Snail in combination with Smad3/4 [37]. Our data is consistent with a model in which both ZEB1 and Snail-Smad3/4 can simultaneously repress the human CAR promoter.

\section{Methods}

Additional methods and further details including antibodies are provided in the Additional file 1.

\section{In silico analyses}

Orthologous CAR upstream sequences were exported from the GenBank (http://www.ncbi.nlm.nih.gov) or Ensemble (http://www.ensembl.org) database according to the positions of the predicted translational start ATG 
(Additional file 1, Table S1). The sequence alignment was performed with CLUSTAL W 1.83 [38] with subsequences $(-25$ to +60 relative to the " $C$ " of the CACCTG E2 box corresponding to E2 box 1 in Figure 1A and 1B) encoded within the $-291 /-1$ region of the human CXADR (CAR) gene. Conserved nucleotides of the aligned sequences were shaded with BOXSHADE
3.21 (http://www.ch.embnet.org/software/BOX_form. html). A stretch of dog CAR sequence previously not available in public databases was sequenced at the University of California, San Francisco (UCSF) Helen Diller Family Comprehensive Cancer Center (HDFCCC) Genome Core (San Francisco, CA, USA) using PCR-amplified genomic DNA extracted from

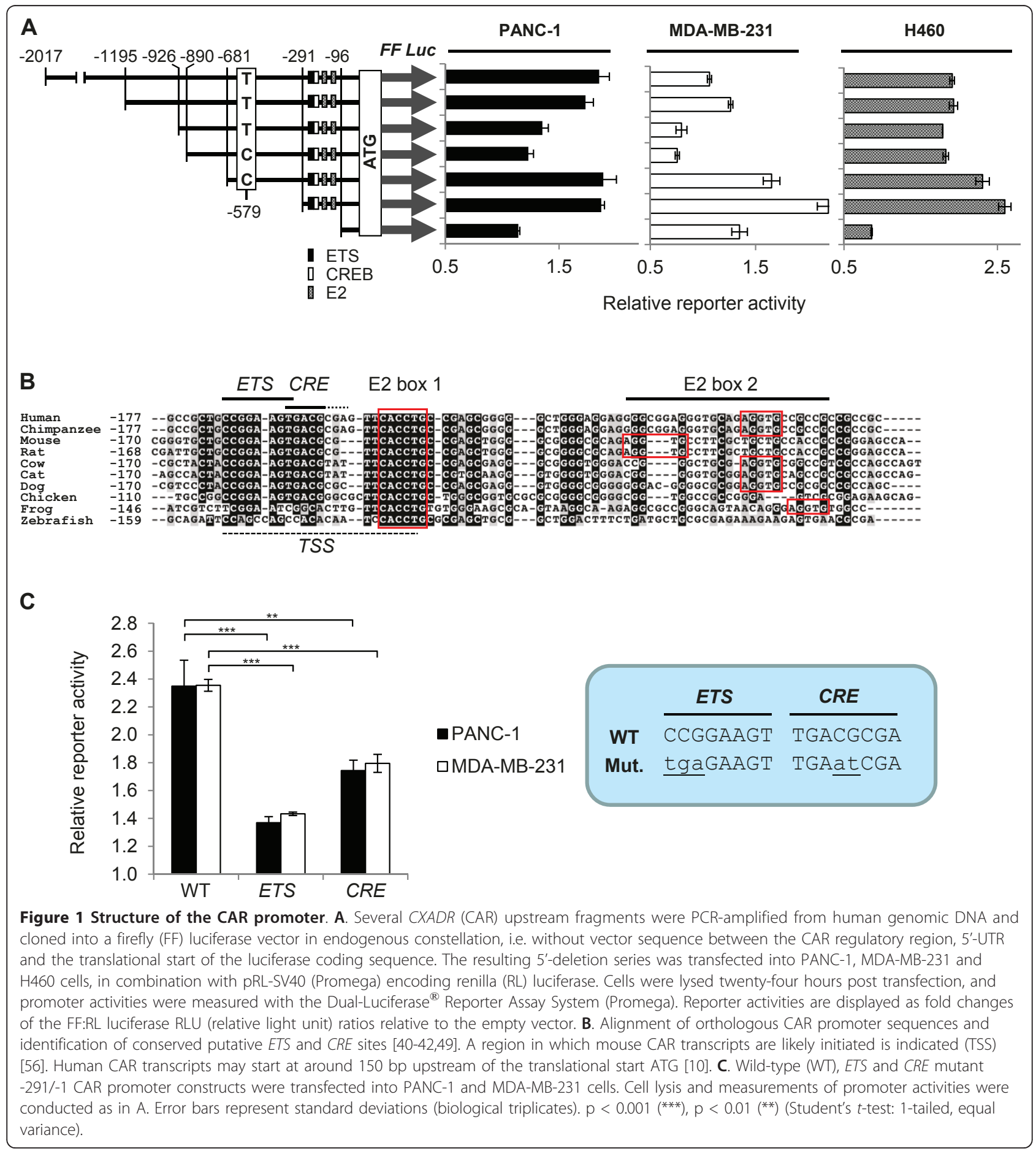


MDCK-Tetoff-SIP1 cells [39] as template. The obtained sequence was submitted to the GenBank database (NCBI, accession number EU744539). In Figure 1B highlighted ETS and cAMP responsive element (CRE) elements are represented by or are highly similar to TRANSFAC $^{\circledR}[40]$ consensus sequences [ETS: TRANSFAC $^{\circledR}$ acc. \# R02153 (ETS1\$CONS, SMGGAWGY), CRE: TRANSFAC ${ }^{\circledR}$ acc. \# R04110 (CREB\$CONS_01, TGACGTMW), $\mathrm{S}=\mathrm{G}$ or $\mathrm{C}, \mathrm{W}=\mathrm{A}$ or $\mathrm{T}, \mathrm{M}=\mathrm{A}$ or $\mathrm{C}$, $\mathrm{Y}=\mathrm{C}$ or $\mathrm{T}]$ and motifs in published reports (CRE, $[41,42])$.

\section{Cell lines}

The human pancreatic cancer cell line PANC-1 [9], and the human breast cancer cell line MDA-MB-231 (gift from Dr. J. Gray, Lawrence Berkeley National Laboratory) were maintained in Dulbecco's Modified Eagle Medium (DMEM; UCSF Cell Culture Facility, San Francisco, CA, USA) supplemented with 10\% Fetal Bovine Serum (FBS; Valley Biomedical, Inc.; Winchester, VA, USA) and 100 units $/ \mathrm{mL}$ penicillin "G", $100 \mathrm{mcg} / \mathrm{mL}$ streptomycin $\mathrm{SO}_{4}$ (both UCSF Cell Culture Facility), and 5 microgram $/ \mathrm{mL}$ Plasmocin ${ }^{\mathrm{TM}}$ (InvivoGen, San Diego, CA, USA). The human non-small cell lung cancer cell line H460 (gift from Dr. D. Jablons, UCSF) [43] was grown in RPMI-1640 (Gibco/Invitrogen, Carlsbad, CA, USA), supplemented with $10 \% \mathrm{FBS}$, penicillin, streptomycin and Plasmocin (all supplemented components as above).

\section{Constructs}

Various CAR [promoter]-[5'-UTR] fragments were independently PCR-amplified from human genomic DNA and cloned into pGL3Ba-DESneo3N. The sequence between the translational ATG start codons of CAR and luciferase was removed by restriction digestion, followed by ethanol precipitation and re-ligation. Mutations at the E2 boxes, ETS and CRE motifs were introduced into the -291/-1 luciferase construct. Inducible Myc-tagged ZEB1 expression constructs were generated by replacing the mSIP1 coding sequence (cds) of pUHD10.3SIP1 [39] through PCR-amplified human ZEB1 cds. Primer sequences and cloning strategies are provided as supplemental information (Additional file 1).

\section{Immunofluorescence and F-actin staining}

PANC-1 and MDA-MB-231 cells were grown on LabTek $^{\text {TM }}$ Chamber Slides (Nalge Nunc/Thermo Fisher Scientific, Inc., Rockford, IL, USA) and treated with 5 $\mathrm{ng} / \mathrm{mL}$ platelet-derived human TGF- $\beta 1$ (R\&D Systems, Minneapolis, MN, USA) for four days. For E-cadherin staining, cells were fixed with a 1:1 solution of methanol and acetone at $-20^{\circ} \mathrm{C}$, and unspecific epitopes were blocked with $3 \%$ bovine serum albumin (BSA) (Sigma-
Aldrich, St. Louis, MO, USA). Then, cells were incubated for 1 hour with 2 microgram $/ \mathrm{mL}$ of the mouse anti-E-cadherin antibody (clone HECD-1, Invitrogen). For F-actin and vimentin stainings, cells were fixed for 15 min. with IC Fixation Buffer (Invitrogen) and permeabilized for $5 \mathrm{~min}$. with $0.1 \%$ Triton X-100 (Aqua Solutions, Deer Park, TX, USA). Then, unspecific epitopes were blocked with $3 \%$ BSA and cells were incubated for 1 hour with a 1:100 dilution of phalloidin conjugated to Texas $\operatorname{Red}^{\circledR}$ (Invitrogen) or with a 1:100 dilution of the rabbit anti-vimentin antibody (D21H3, Cell Signaling Technology, Inc., Danvers, MA, USA). For E-cadherin and vimentin stainings secondary antibodies conjugated to Alexa Fluor ${ }^{\circledR} 488$ (Molecular Probes/ Invitrogen) were used. Nuclei were stained with DAPI, and samples mounted onto glass slides using Vectashield (Vector Lab, Burlingame, CA, USA). Immunofluorescence images were obtained using a Zeiss Imager Z2 microscope (Carl Zeiss, Jena, Germany) equipped with an AxioCam camera and processed with Axiovision software. Digital images were adjusted for contrast and brightness using Adobe Photoshop CS5.

\section{RNA interference}

PANC-1 cells were pre-treated for two days with $5 \mathrm{ng} /$ $\mathrm{mL}$ platelet-derived human TGF- $\beta 1$ (R\&D Systems), then, and two days later, siRNA-transfected by using Lipofectamine RNAiMax (Invitrogen). TGF- $\beta$ treatment was continued through the first, until two days after the second transfection. MDA-MB-231 cells were similarly transfected, but not stimulated with ectopic TGF- $\beta$. Cell lysis for protein harvest, flow cytometric analysis of cellsurface CAR and adenovirus infections were carried out four days after the initial transfection. Abbreviations: UT, untransfected; Ctrl \#1, siControl ON-TARGETplus Non-targeting siRNA \# 1 (Dharmacon/Thermo Fisher Scientific, Inc.); Ctrl \#2, firefly luciferase-targeting siRNA; ZEB1 siRNA \#1/\#2, ZEB1-targeting siRNAs. Ctrl \#2 and ZEB1 siRNA sequences are provided in Additional file 1 (Table S3) and were obtained by using the siDESIGN ${ }^{\circledR}$ Center (Dharmacon/Thermo Fisher Scientific, Inc.). Detailed information is provided as supplemental information (Additional file 1).

\section{Expression analysis by real-time RT-PCR}

Total RNA was extracted with the RNeasy kit (Qiagen, Valencia, CA, USA). Reverse-transcription and real-time PCR were carried out at the UCSF HDFCCC Genome Core with the primer/probe sequences listed in Additional file 1 (Table S3) and with Expression Assays (Applied Biosystems, Foster City, CA, USA) for CDH1 (E-cadherin, Hs00170423_m1), ZEB1 (Hs00611018_m1 or Hs00232783_m1), ZEB2 (SIP1, Hs00207691_m1), SNAI1 (Snail, Hs00195591_m1), SNAI2 (Slug, Hs00161904_m1) 
and SERPINE1 (PAI-1, Hs01126604_m1). Data were analyzed by relative quantitation [44].

\section{Immunoblotting and cell fractionation}

Antibodies used include rabbit anti-phospho-Smad2 (Ser465/467, Cell Signaling Technology, Inc.), goat antiZEB1 (E-20, Santa Cruz Biotechnology, Inc., Santa Cruz, CA, USA), mouse anti- $\beta$-tubulin (Sigma-Aldrich), mouse anti-PARP (clone C2-10, Pharmingen/BD Biosciences, San Jose, CA, USA), mouse anti-GAPDH-Peroxidase Conjugate (Sigma-Aldrich), and mouse anti-Myc Tag (clone 4A6; Upstate/Millipore, Charlottesville, VA, USA). Cell fractionation was carried out via the NEPER $^{\circledR}$ Nuclear and Cytoplasmic Extraction Reagents kit (Pierce/Thermo Fisher Scientific, Inc.). A description of the Western blot procedure and further antibody references are provided elsewhere [9].

\section{Luciferase reporter assays}

All transfections involving CAR promoter constructs were carried out by using FuGENE HD (Roche, Indianapolis, IN, USA) (3 microliter per 1 microgram of DNA), and included co-transfection of the renilla luciferase-encoding pRL-SV40 plasmid (Promega, Madison, WI, USA) for normalization. Cells were subconfluent at the time of transfection. For the identification of the CAR promoter, cells were grown in 24-well plates and transfected with 750 nanogram of the pGL3Ba-DESneo3N reporter plasmids in combination with 10 nanogram pRL-SV40. To transfect equimolar amounts of each CAR promoter construct of the CAR upstream 5'deletion series, plasmid size differences were compensated by co-transfection with the pGL3Ba-DESneo3NEmVec empty vector plasmid. For the characterization of the ETS and CRE elements, cells were grown in 6well plates and transfected with 3 microgram of wildtype, ETS or CRE element-mutated -291/-1 luciferase construct in combination with 50 nanogram pRL-SV40. For the characterization of the E2 boxes as binding sites for ZEB1, cells were grown in 24-well plates and transfected with 500 nanogram of wild-type and E2 box-mutated -291/-1 luciferase construct, 125 nanogram pRevTet-Off (Clontech Laboratories, Inc./Takara Bio, Inc., Otsu, Shiga, Japan), and 375 nanogram pTRE-6Myc-deltaATG-hZEB1 in combination with 10 nanogram pRL-SV40. 4-6 hours post transfection, the transfection medium was removed, and around 1.5-2 hours later, stimulation with 2 microgram $/ \mathrm{mL}$ doxycyline hyclate (Sigma-Aldrich) was begun. Cells were lysed twenty-four (to define the minimal CAR promoter and to characterize ETS and CRE elements) or forty-eight (to assess effects of Myc-ZEB1 on the WT and mutant CAR promoter) hours post transfection with Passive Lysis Buffer (Promega). Reporter activities were measured with the Dual-Luciferase ${ }^{\circledR}$ Reporter Assay System (Promega).

\section{Biotinylated Oligonucleotide Precipitation Assay}

One day after seeding $3 \times 10^{6}$ PANC-1 cells per $10 \mathrm{~cm}$ dish, cells were transiently co-transfected with pRevTetOff (4.0 microgram) (Clontech Laboratories, Inc./Takara Bio, Inc.) in combination with pTRE-6Myc-deltaATGhZEB1 (12.0 microgram) by using FuGENE HD (Roche) (3 microliter per 1 microgram of DNA). Control lysates were made from PANC-1 cells seeded at a density of 5 $\times 10^{5}$ cells per well (6-well plate) and transfected with the same plasmids. Four hours post transfection, transfection medium was replaced by antibiotic-containing full medium. Six hours post transfection, medium was again replaced by full medium with (to repress ZEB1) or without (to induce ZEB1) 2 microgram $/ \mathrm{mL}$ doxycycline hyclate (Sigma-Aldrich). Forty-eight hours after transfection, oligonucleotide precipitations were carried out following a modified version of the procedure described by others $[39,45]$. ZEB1 was detected with the mouse monoclonal anti-Myc Tag clone 4A6 (Upstate/Millipore) antibody at 1 microgram $/ \mathrm{mL}$. Detailed information is provided as supplemental information (Additional file 1).

\section{Chromatin Immunoprecipitation}

PANC-1 cells were transiently transfected with pTRE6Myc-deltaATG-hZEB1 in combination with pRevTetOff (Clontech) using FuGENE HD (Roche). For the control sample, six hours after addition of the plasmid DNA to the cells, expression of Myc-ZEB1 was suppressed with 2 microgram $/ \mathrm{mL}$ doxycyline hyclate (Sigma-Aldrich). The next day, cells of both control and experimental samples were stimulated with $5 \mathrm{ng} / \mathrm{mL}$ platelet-derived human TGF- $\beta 1$ (R\&D Systems). Fortyeight hours after transfection, chromatin was crosslinked with paraformaldehyde and subjected to Chromatin Immunoprecipitation (ChIP) at the University of California at Davis (UC Davis) Genome Center (CA, USA), following a protocol developed by the Farnham laboratory (UC Davis, Davis, CA, USA) (http://www.genomecenter.ucdavis.edu/farnham/pdf/FarnhamLabChIP\% 20Protocol.pdf). In short, samples were sonicated using a BioRuptor ${ }^{\mathrm{TM}}$ Sonicator (Diagenode, Inc.; Sparta, NJ, USA), DNA was precipitated with an anti-Myc Tag antibody (clone 4A6; Upstate/Millipore), and SYBR Green I real-time PCR with the precipitated DNA as template was conducted using the $\mathrm{iQ}^{\mathrm{TM}} \mathrm{SYBR}^{\circledR}$ Green Supermix (Bio-Rad Laboratories, Hercules, CA, USA) using CAR promoter-specific primers (Additional file 1, Table S3).

\section{Adenovirus infections}

Following a four-day siRNA treatment period, PANC-1 cells were infected with $300 \mathrm{microliter} /$ well (12-well 
plates) Ad-GFP [9] diluted in DMEM (UCSF Cell Culture Facility) supplemented with 2\% FBS (Valley Biomedical, Inc.) at a Multiplicity Of Infection (MOI) of 200. Ninety minutes post-infection, virus was replaced by regular growth medium. Twenty-four hours postinfection, Ad-GFP uptake was analyzed by both flow cytometry (GFP intensities) and real-time PCR (virus copy numbers). For the latter approach genomic/adenoviral DNA was first extracted with the DNeasy ${ }^{\circledR}$ Blood \& Tissue kit (Qiagen) and then subjected to ethanol precipitation to potentially improve DNA quality. Relative virus copy numbers were determined at the UCSF HDFCCC Genome Core by TaqMan PCR amplification of the adenovirus fiber gene (primer/ probe sequences shown in Additional file 1, Table S3) normalized to genomic DNA amplified with a pool of primers for D1S2868, D2S385, D4S1605, D5S643, D10S586, and D11S1315 [46]. Data were analyzed by relative quantitation [44].

\section{Flow cytometry}

Live cells were stained with an anti-CAR-phycoerythrin (PE) antibody (E1-1, mouse monoclonal; Santa Cruz Biotechnology, Inc.) or PE-conjugated control IgG-PE (mouse monoclonal IgG1 $\kappa$, Pharmingen/BD Biosciences) while rotating for 60 minutes at $4^{\circ} \mathrm{C}$. Cells were then washed and resuspended in 1 micromolar TO$\mathrm{PRO}^{\mathbb{R}}$-3 iodide (TP3, for exclusion of dead cells) (Invitrogen) in PBS supplemented with 5\% FBS, and analyzed by flow cytometry using FACSCalibur (BD Biosciences) or Accuri C6 (Accuri Cytometers, Inc., Ann Arbor, MI, USA/BD, Franklin Lakes, NJ, USA) flow cytometers. Cell-surface CAR was detected in the FL2 channel, nonviable cells, stained by TP3 and detected in the FL4 channel, were excluded. For the analysis of live Ad-GFP infected cells, GFP was detected in the FL1 channel. TP3-positive cells were excluded. Data analysis was carried out with Cyflogic ${ }^{\mathrm{TM}}$ software (CyFlo Ltd, Turku, Finland). Detailed information is provided as supplemental information (Additional file 1).

\section{Results}

\section{Defining the CAR promoter}

TGF- $\beta$ down-regulates CAR mRNA and protein levels [9]. Since neither mRNA nor protein stability appeared to be affected by TGF- $\beta$ [9], regulation of CAR expression likely occurs at the promoter level. Bowles et al. reported that the locus of the functional human CAR gene $(C X A D R)$ is on chromosome 21, 21q11.2 [47]. However, even though 21q11 harbors CAR sequence, this locus encodes a CAR pseudogene lacking introns. The functional human CAR gene is located on 21q21.1 (Entrez Gene, Gene ID: 1525, NCBI).
To experimentally determine the CAR promoter region we cloned several fragments of CAR upstream sequence as a 5'-deletion series into pGL3Ba-DESneo3N (a luciferase reporter vector we engineered allowing recombination-based cloning of [promoter]-5'-UTR fragments in endogenous constellation, i.e. without vector sequence between the regulatory fragments and the luciferase coding sequence (Figure 1A). To identify genomic regions involved in the regulation of CAR expression, we transfected the 5'-deletion series into PANC-1 (human pancreatic cancer), H460 (human non-small cell lung cancer), and MDA-MB-231 (human breast cancer) cells. In all cell lines, reporter activities were higher for the genomic fragments $-2017 /-1,-1195 /-1,-681 /-1$, $-291 /-1$ than for $-926 /-1$, and $-890 /-1$ (Figure 1A). This may suggest that silencer elements are present between -1194 and -682 , and that positive regulatory elements further upstream override this negative regulation. In all cell lines, maximal promoter activity was measured with the $-291 /-1$ construct, whereas the $-96 /-1$ fragment was only minimally active. Therefore, the CAR core promoter, which interacts with the DNA polymerase II complex, and the adjacent proximal promoter [48], are located within -291 and -1 relative to the translational start ATG. This is in agreement with a previous report by Pong et al. illustrating that CAR transcription is likely initiated at around -150 relative to the ATG [10].

Since each promoter/5'-UTR fragment was individually PCR-amplified we were able to identify a single nucleotide polymorphism (SNP) at position -579 , with the base being either thymine (in the $-2017 /-1,-1195 /-1$, $-926 /-1$ fragments) or cytosine $(-890 /-1$ and $-681 /-1$ fragments). It is unlikely that this SNP influences CAR expression, since the reporter activities of the $-926 /-1$ and the $-890 /-1$ fragments, which differ only in $36 \mathrm{bp}$, are very similar, despite the polymorphic difference (Figure $1 \mathrm{~A}$ and data not shown).

By aligning CAR upstream sequences from diverse species ranging from zebrafish to man, several conserved elements were recognized within the $-291 /-1$ fragment: putative binding sites for ETS transcription factors and for c-AMP responsive element $(C R E)$ binding protein (CREB) $[41,42,49]$, as well as two closely spaced E2 boxes (Figure 1B). The latter elements are particularly interesting since they are located in a similar genetic context than the E2 boxes in the human Ecadherin promoter to which E2 box-binding repressors such as SIP1 [23,33,35,39] and ZEB1 [25,33-36] bind. To investigate whether the ETS and CRE elements are biologically relevant, we transiently transfected PANC1 and MDA-MB-231 cells with ETS or CRE mutant $-291 /-1$ luciferase constructs. Inactivation of either motif reduced CAR promoter activity, suggesting that 
both ETS and CREB factors may induce CAR expression (Figure 1C).

\section{Down-regulation of CAR in TGF- $\beta$-induced EMT}

The presence of the dual E2 box motif in the CAR promoter suggests that SIP1 and/or ZEB1 repress(es) CAR expression upon TGF- $\beta$ treatment in cells undergoing EMT. If true, SIP1 and/or ZEB1 expression may be stimulated by TGF- $\beta$. We chose PANC- 1 cells as an EMT model in this study as these cells are known to undergo TGF- $\beta$-induced EMT $[9,50]$. In agreement, untreated cells stained positive for cell surface E-cadherin but not for vimentin intermediate filaments or F-actin, thus demonstrating epithelial characteristics (Figure 2). Conversely, TGF- $\beta$ induced an EMT process in PANC-1 cells as shown by lack of E-cadherin staining. In contrast, MDA-MB-231 cells did not express cell surface Ecadherin, but strongly stained positive for vimentin filaments or F-actin, thus demonstrating mesenchymal features (Figure 2). To address whether SIP1 and/or ZEB1 may affect CAR expression upon TGF- $\beta$ stimulation, we measured their mRNA levels in PANC-1 and MDAMB-231 cells. In agreement with the data obtained by immunofluorescence (Figure 2), MDA-MB-231 cells demonstrated mesenchymal features (lack of E-cadherin expression and high SIP1 and ZEB1 levels) (Figure 3BD). It is of note that the cells used in this study are morphologically markedly different and may proliferate faster than MDA-MB-231 cells from the American Type Culture Collection (ATCC, Manassas, VA), and likely represent a derivative of the cell line. In agreement with our previous report, in PANC-1 cells, both CAR and Ecadherin mRNA levels were reduced as consequence of TGF- $\beta$ treatment (Figure 3A and 3B) [9], while ZEB1 expression was modestly stimulated (Figure 3D). Despite the presence of a dual E2 box sequence in the CAR promoter single E2 box-binding repressors, such as Snail and Slug, may regulate CAR expression upon TGF- $\beta$ stimulation. Indeed, PANC- 1 cells responded to TGF- $\beta$ stimulation with increased Snail expression (Figure 3E). This data is consistent with a recent report demonstrating that Snail-Smad3/4 is a physiological regulator of

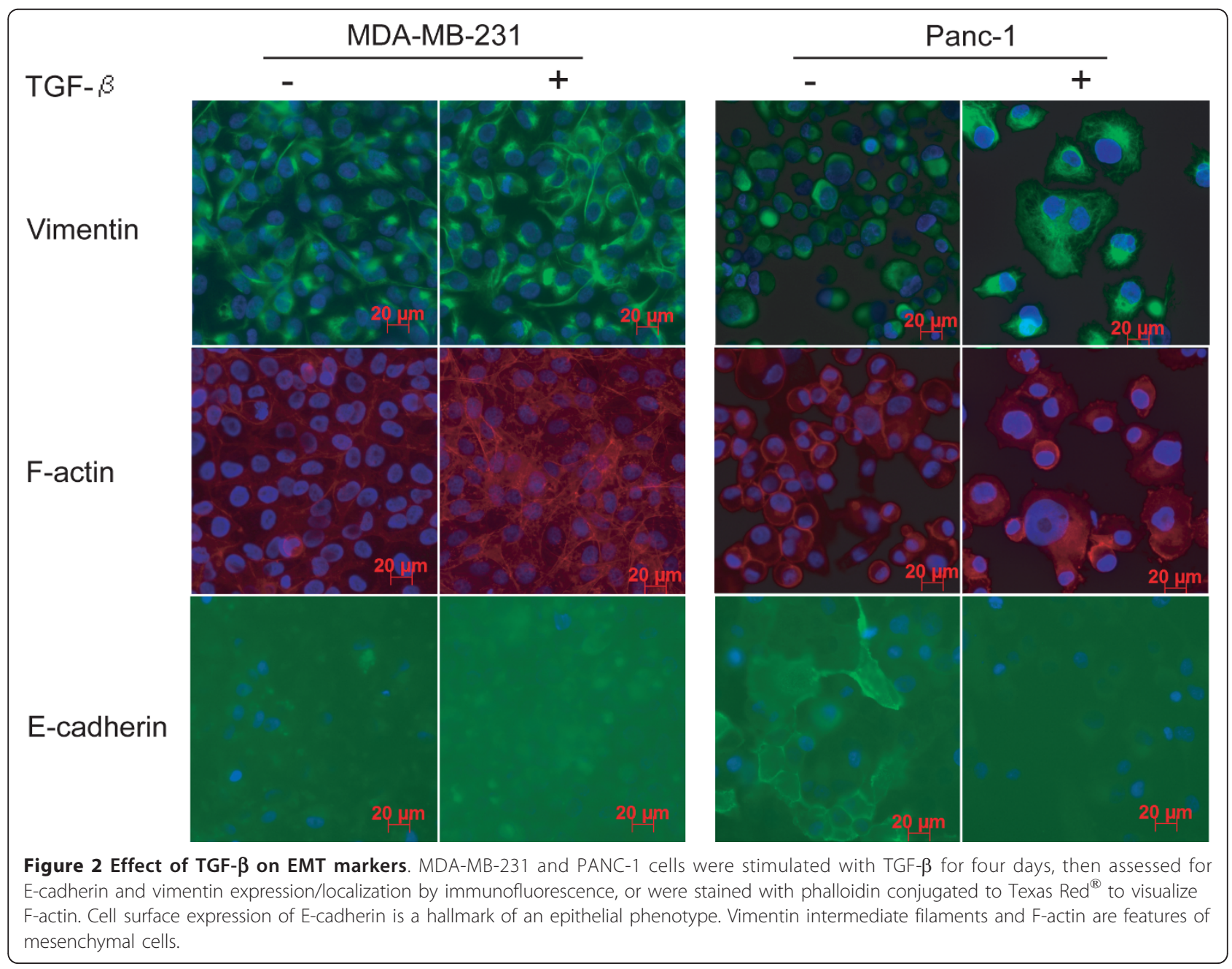


CAR in murine cells [37]. In addition to Snail, also Slug mRNA levels increased in PANC-1 cells following addition of TGF- $\beta$. However, as they remained low, Slug is not likely a regulator of CAR in these cells. Interestingly, despite their mesenchymal features, MDA-MB-231 cells expressed relatively high CAR levels (Figure 3A), and, similarly to PANC-1 cells, also down-regulated CAR upon TGF- $\beta$ treatment. However, in MDA-MB-231 cells, TGF- $\beta$ stimulated Slug expression, suggesting that in this cell line Slug potentially inhibits CAR expression (Figure 3F).

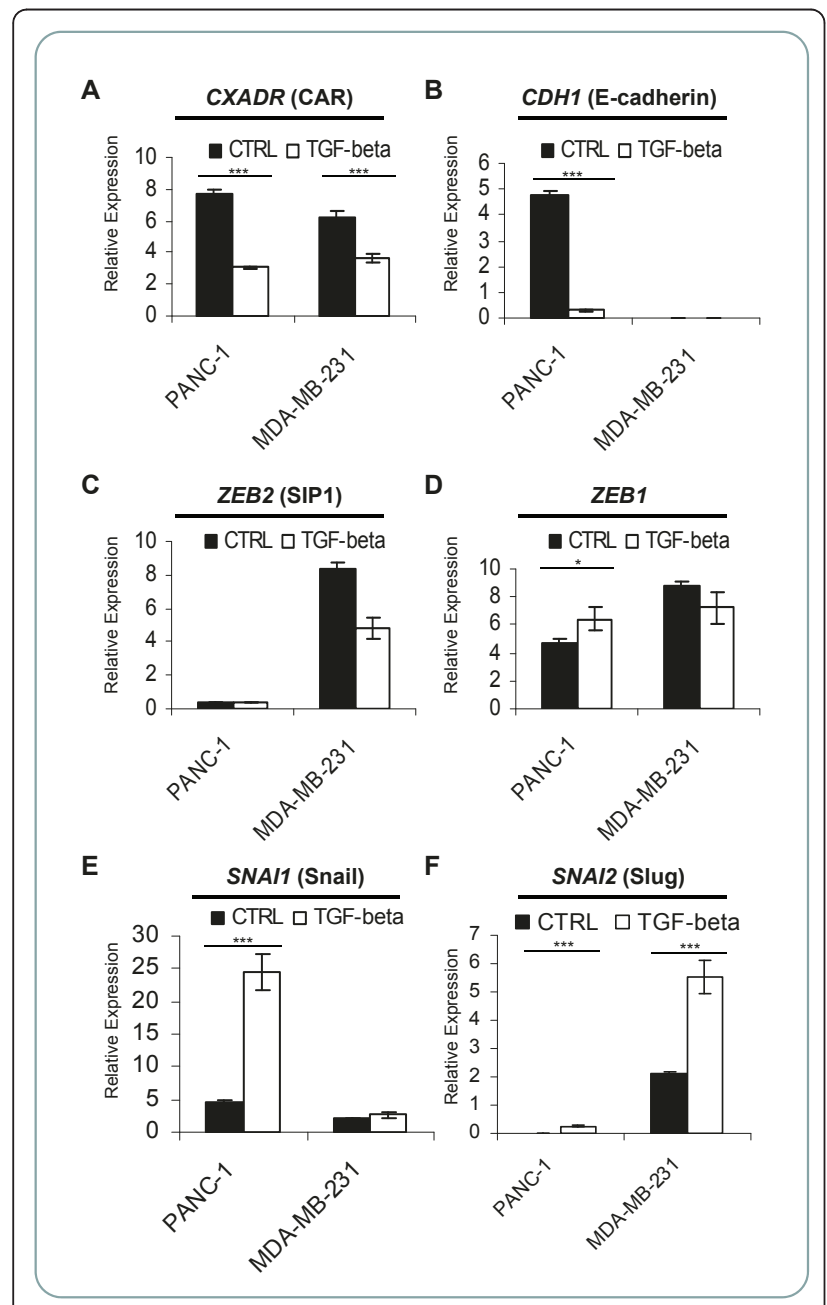

Figure 3 E2 box-binding repressor expression upon TGF- $\beta$ stimulation. PANC-1 and MDA-MB-231 cells were treated with recombinant human TGF- $\beta 1$ for four days. mRNA expression of CXADR (CAR) (A), CDH1 (E-cadherin) (B), ZEB2 (SIP1) (C), ZEB1 (D), SNAl1 (Snail) (E), and SNAI2 (Slug) (F) was measured by TaqMan realtime PCR. Expression data were normalized to H3F3A ( $\mathrm{H} 3$ histone, family 3A) mRNA levels (arbitrary units). A-F. Error bars represent standard deviations (biological triplicates). $\left.p<0.001{ }^{(* *}\right), p<0.01$ $\left.\left.{ }^{(* *}\right), p<0.05{ }^{*}\right)$ (Student's t-test: 1-tailed, equal variance). Absence of * indicates $p \geq 0.05$, or decrease of E2 box-binding repressor expression upon TGF- $\beta$ stimulation.

\section{E2 box-dependent repression of the human CAR} promoter by ectopic ZEB1

A recent study indicates that CAR may be transcriptionally repressed by Snail-Smad3/4 in TGF- $\beta$ stimulated murine epithelial cells [37]. However, microarray data suggests that siRNA-mediated knockdown of ZEB1 in human MDA-MB-231 cells may increase CAR mRNA levels [34]. Given the above described orthologously conserved nature of the E2 boxes in the CAR promoter, we hypothesized that the suggested repression of CAR is mediated by ZEB1 by directly repressing the CAR promoter at the E2 boxes, and is not an indirect consequence of the MET induced by the knockdown of ZEB1. To test this hypothesis, we co-transfected PANC1 cells with an inducible Myc-tagged human ZEB1 expression plasmid, in combination with wild-type or E2 box-mutant CAR promoter reporter constructs. Induction of ZEB1 was performed in the context of a "TetOFF" system, in which the presence of doxycycline repressed ZEB1 expression, and carried out as a "dual luciferase" approach in which firefly (FF) luciferase was driven off the CAR promoter, and renilla (RL) luciferase was expressed through an SV40 promoter. While induction of ZEB1 repressed the wild-type CAR promoter, it also repressed the single E2 box-mutant promoters (Bx1, Bx2), although to a lesser degree. Repression of the CAR promoter was further reduced when both E2 boxes $(\mathrm{Bx} 1+2)$ were inactivated. Importantly, compared to the wild-type promoter, all mutations resulted in significantly $(\mathrm{p}<0.05)$ higher relative promoter activities in the presence of ZEB1 suggesting that ZEB1 indeed represses the CAR promoter E2 box-dependently (Figure $4 \mathrm{~A})$. It is important to note that a determination of the exact percentage of repression appeared not possible with the chosen dual luciferase approach, as various CAR promoter-independent factors affected the expression of both FF and RL luciferase. However, when correcting for such parameters mathematically (data not shown), several types of adjustment revealed stronger repression of the wild-type compared to the dual E2 box-mutant $(\mathrm{Bx} 1+2) \mathrm{CAR}$ promoter.

The presence of the dual E2 box motif suggests that, in addition to ZEB1, also SIP1 may repress the CAR promoter. Indeed, overexpression of Myc-tagged SIP1 [39] repressed CAR promoter activity E2 box-dependently (data not shown). However, since TGF- $\beta$ neither increased SIP1 mRNA expression, nor are the SIP1 mRNA levels high in PANC-1 cells (Figure 3C) SIP1 is unlikely the main regulator of CAR in TGF- $\beta$-mediated EMT in our PANC-1 system.

\section{ZEB1 binds to the CAR promoter}

To determine whether ZEB1 indeed physically binds to the $\mathrm{E} 2$ boxes in the CAR promoter, we overexpressed 
Myc-tagged human ZEB1 in PANC-1 cells and incubated the cell extracts with biotinylated oligonucleotides composed of a region of the CAR promoter containing the two E2 boxes (Additional file 1, Table S3). A similar strategy was used to elegantly demonstrate binding of SIP1 to the E-cadherin promoter [39]. Following pulldown with streptavidin-conjugated agarose resin, MycZEB1 was detected by conventional Western blotting with an anti-Myc tag antibody. A strong signal was obtained with the oligonucleotides representing both wild-type and E2 box 2-mutant CAR promoter sequence. A mutation in either only E2 box 1 or in both E2 boxes prevented binding of ZEB1 to the oligonucleotides (Figure 4B). We conducted the same assay with Myc-tagged SIP1 [39] and, interestingly, observed a similar binding pattern (data not shown). However, as outlined above, SIP1 is unlikely the main repressor of CAR in TGF- $\beta$-mediated EMT in PANC- 1 cells. Taken together, our data indicate that ZEB1 interacts with E2 box 1 but not with E2 box 2 (see Figure 1A for the location of E2 box 1 and 2 within the CAR promoter). It is conceivable that ZEB1 might still require both E2 boxes in the CAR promoter for binding, but the point mutation in E2 box 2 was insufficient to prevent binding (Figure 4C).

To ascertain whether ZEB1 also binds to the chromosomal CAR promoter in PANC-1 cells stimulated with TGF- $\beta$, a Chromatin Immunoprecipitation (ChIP) assay was conducted with cells transiently transfected with inducible Myc-ZEB1. As demonstrated in Figure 4D, precipitation of CAR DNA with an anti-Myc Tag antibody was apparent when Myc-ZEB1 was induced, suggesting binding of ZEB1 to genomic CAR promoter sequence. Nevertheless, some binding was also observed when Myc-ZEB1 was repressed (Figure 4D). However, this latter effect is likely due to leakiness of the system allowing some Myc-ZEB1 expression even in the presence of the repressor (doxycycline) (Figure 4E and Additional file 1, Fig. S1). As determined from sample aliquots removed prior to crosslinking, total ZEB1 mRNA levels were approximately 30 fold higher in the ChIP experiment following induction of Myc-ZEB1 expression by absence of doxycycline (Figure 4E).

\section{ZEB1 represses CAR in mesenchymal cells}

We sought to investigate whether ZEB1 also contributes to the repression of CAR in PANC-1 cells in the context of TGF- $\beta$-mediated EMT, and whether it mediates CAR repression in established mesenchymal MDA-MB-231 cells. TGF- $\beta$ reduces both CAR and E-cadherin protein levels in the absence but not in the presence of ZEB1 siRNA suggesting that the TGF- $\beta$-induced repression of either protein requires ZEB1 (Figure 5A). Similarly, ZEB1 plays a pivotal role in maintaining mesenchymal characteristics of MDA-MB-231 cells, since siRNAmediated knockdown of ZEB1 induces a partial MET, illustrated by the up-regulation of epithelial markers such as CAR and E-cadherin, or the down-regulation of the mesenchymal marker fibronectin (Figure 5A and [34]). Interestingly, even though both siRNAs reduced ZEB1 protein levels similarly, transfection of PANC-1 cells with siRNA \#2 down-regulated phospho-Smad2 (Figure 5A). Since ZEB1 siRNA \#2 has a seed region that is $100 \%$ complementary to a region within the 3'UTR of phosphoinositide-3-kinase, regulatory subunit 1 (alpha) (PIK3R1, Entrez Gene, Gene ID: 5295, NCBI) [51], the effect on Smad2 might have been a consequence of reduced PI3K activity. The requirement of PI3K signaling for TGF- $\beta 1$-mediated C-terminal phosphorylation of Smad2 was previously demonstrated in NMuMG cells [52].

\section{TGF- $\beta$ does not affect ZEB1 protein levels or subcellular localization}

While TGF- $\beta$ only minimally up-regulated ZEB1 mRNA in PANC-1 cells (Figure 3D and Additional file 1, Fig. $\mathrm{S} 1$ ), effects at the protein level varied: some (Figure 5A) but not all (Figure 5B) experiments suggested that stimulation by TGF- $\beta$ increases the total ZEB1 protein levels. To address this question systematically, we measured ZEB1 protein levels over time, with harvests of the total protein fractions in twenty-four hour intervals. Indeed, while CAR was down-regulated at every time point in the TGF- $\beta$-treated samples, ZEB1 levels remained unchanged throughout the time-course (Figure $5 \mathrm{~B})$. To investigate whether TGF- $\beta$ promotes nuclear entry of ZEB1 as a mechanism to increase the latter protein's activity as a transcriptional repressor of CAR, we measured ZEB1 protein levels in both nuclear and cytoplasmic fractions. Interestingly, ZEB1 appears to be exclusively localized in the nucleus, both in the presence and absence of TGF- $\beta$. In agreement with the total ZEB1 protein data, TGF- $\beta$ stimulation for fortyeight hours did not increase the nuclear ZEB1 levels (Figure 5C).

ZEB1 is necessary for TGF- $\beta$-induced EMT in PANC-1 cells As demonstrated above, ZEB1 total, nuclear and cytoplasmic protein levels were little affected by TGF- $\beta$, whereas knockdown experiments suggested that ZEB1 is a critical component of the TGF- $\beta$-induced EMT process in PANC-1 cells (Figure 5A-B). To address this dilemma, we tested the hypothesis that TGF- $\beta$ can activate ZEB1 rather than increase its protein levels. However, in reporter assays carried out with PANC-1 cells, TGF- $\beta$ did not appear to enhance the repressor effect of overexpressed ZEB1 on the CAR promoter (data not shown). Still, even though this data does 


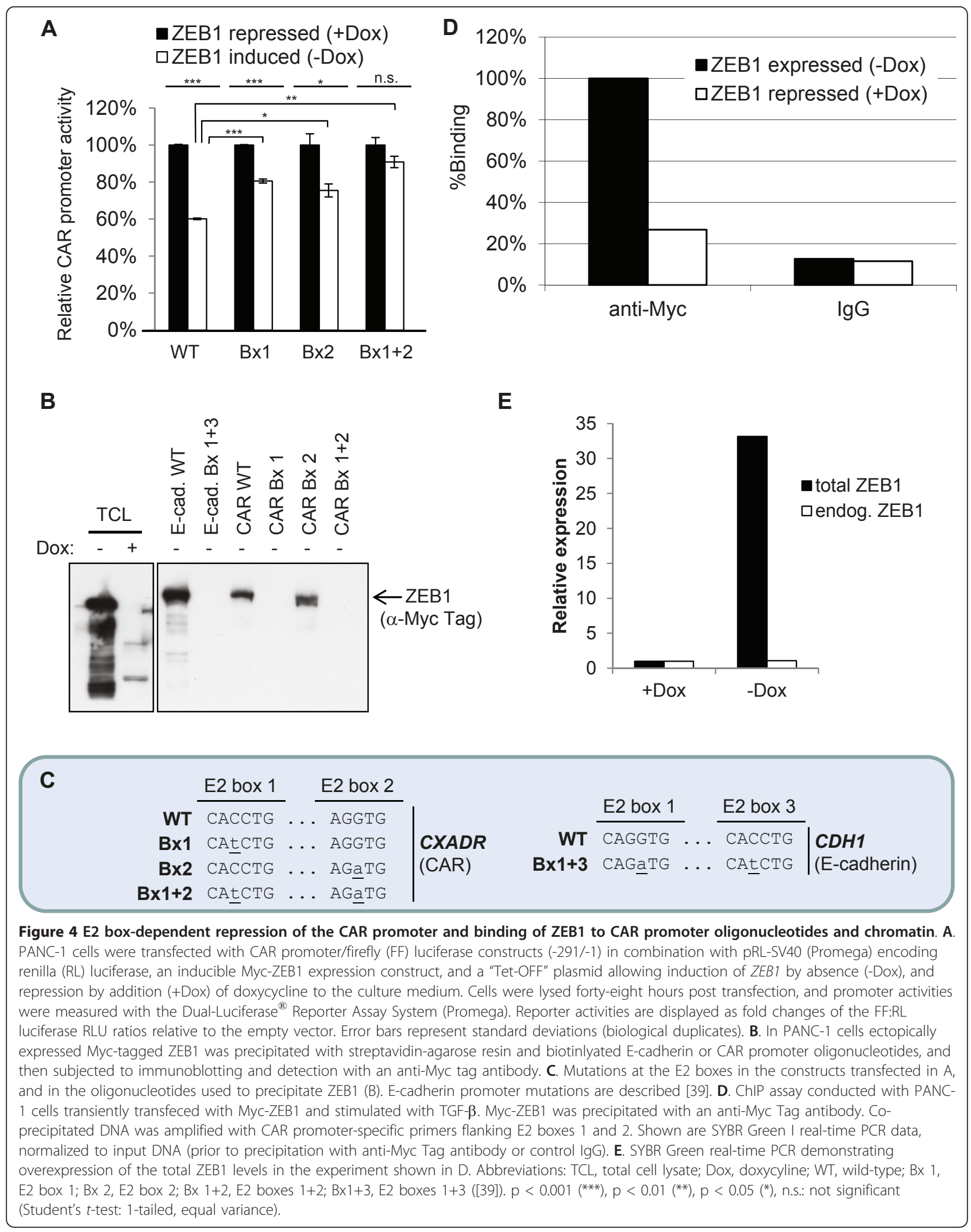


A
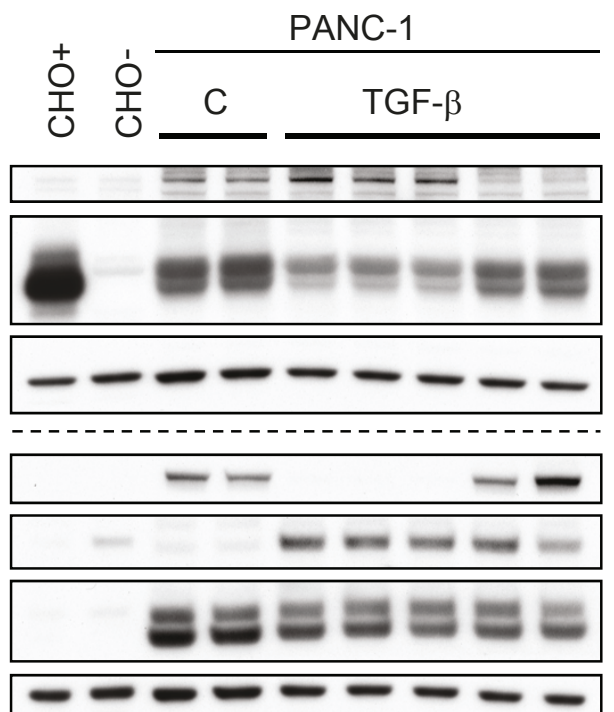

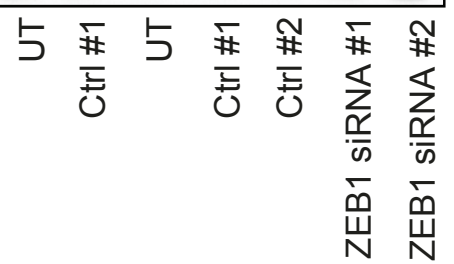

B
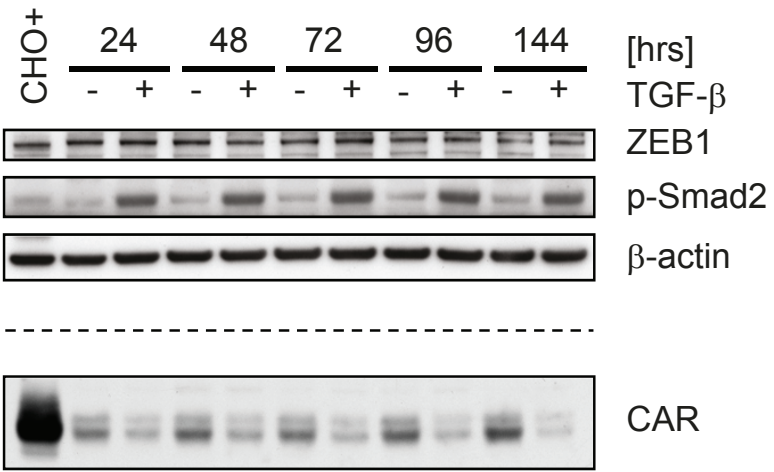

CAR
p-Smad 2

<Smad 2

$\kappa_{\text {Smad } 3}$ GAPDH

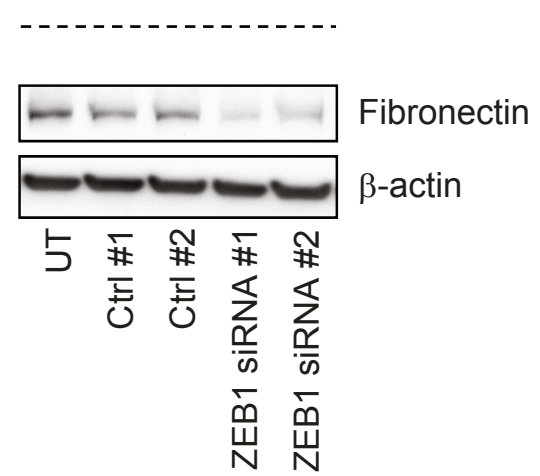

C

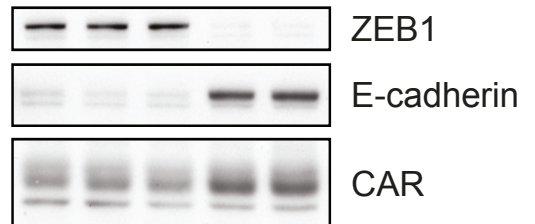

$-\infty-\beta$-tubulin

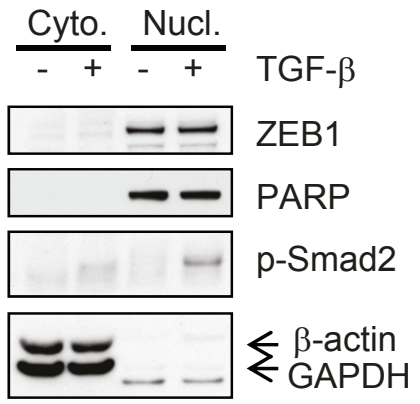

$\ldots-\ldots-\ldots-\ldots$

$\beta$-Tubulin

Figure 5 ZEB1 promotes EMT. A-C. Immunoblots. PANC-1 cells were pre-treated with TGF- $\beta 1$ for two days and then transfected twice (day 0 and day 2) with ZEB1 siRNAs in the continued presence of TGF- $\beta$ 1. Four days after the initial transfection, cells were harvested. A. By upregulating epithelial proteins such as E-cadherin and CAR, knockdown of ZEB1 antagonizes TGF- $\beta$-induced EMT in PANC-1 cells. Similarly, silencing of ZEB1 expression in MDA-MB-231 cells up-regulates E-cadherin and CAR, and down-regulates the mesenchymal marker fibronectin. B. PANC-1 cells were treated with TGF- $\beta 1$, and harvested at the indicated time-points for analysis of the total protein fractions. C. PANC-1 cells were treated with TGF- $\beta 1$ and subjected to cell fractionation. Abbreviations: C, TGF- $\beta 1$ solvent control $[4 \mathrm{mM} \mathrm{HCl} / 0.1 \%(\mathrm{~V} / \mathrm{W}) \mathrm{BSA}]$; UT, untransfected; Ctrl \#1, siControl ON-TARGETplus Non-targeting siRNA \#1 (Dharmacon); Ctrl \#2, firefly luciferase-targeting siRNA; ZEB1 siRNA \#1/\#2, ZEB1-targeting siRNAs. Ctrl \#2 and ZEB1 siRNA sequences are provided in Additional file 1 (Table S3). Chinese Hamster Ovary cells stably expressing human $\mathrm{CAR}(\mathrm{CHO}+$ ), or vector (CHO-) [9]. Loading controls are shown as $\beta$-actin, $\beta$-tubulin, GAPDH and PARP signals, with GAPDH as a cytoplasmic, and PARP as a nuclear marker.

not support our hypothesis, the real effect of TGF- $\beta$ on ZEB1 may have been masked as ZEB1 was likely highly overexpressed (Additional file 1, Fig. S1). Alternatively, our data is consistent with a model in which ZEB1 constitutively binds to one of the two E2 boxes
(E2 box 1, Figure 4B) in the CAR promoter thereby controlling the basal levels of CAR. TGF- $\beta$ may further repress the CAR promoter via the second E2 box (E2 box 2), for instance by activating Snail-Smad3/4 [37] (Figure 6). 


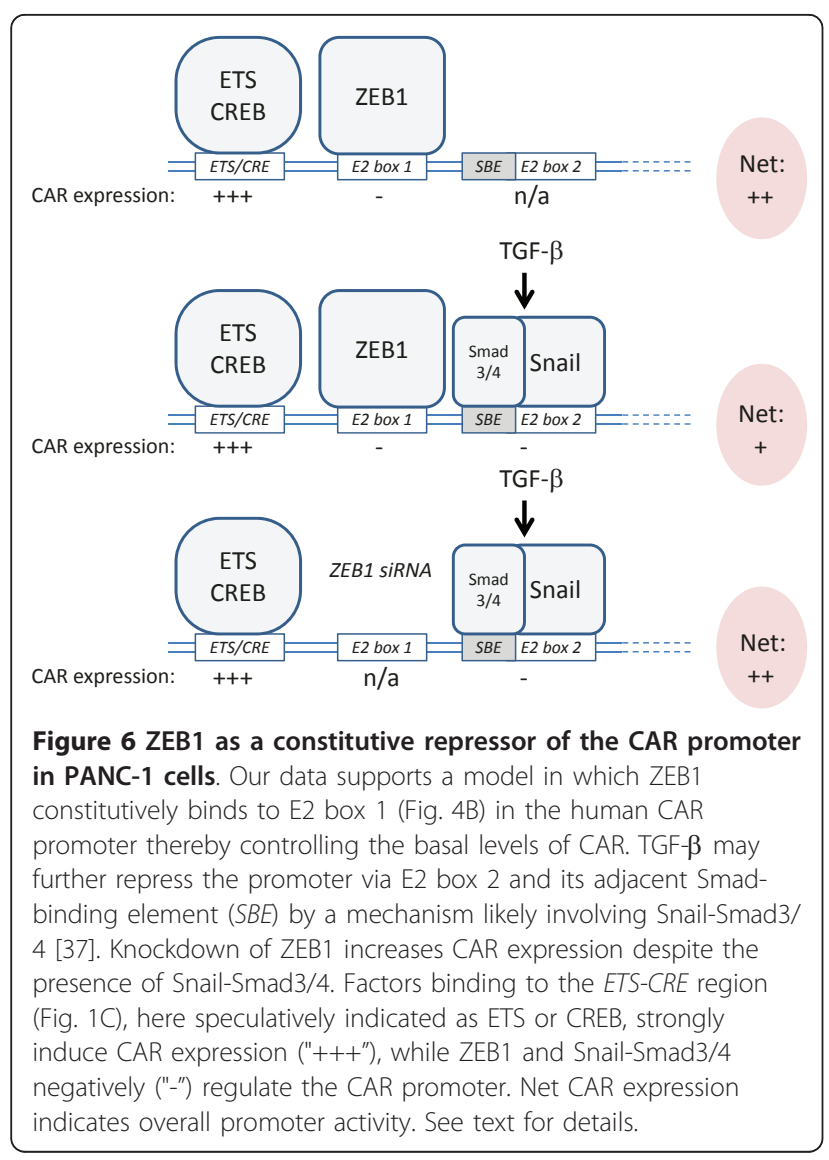

ZEB1 knockdown facilitates adenovirus uptake

An increase in CAR expression following ZEB1 knockdown may improve therapies with oncolytic adenoviruses if it translates into elevated cell-surface CAR levels [3]. We addressed this question in both PANC-1 EMT, and MDA-MB-231 MET models. In the former system, we employed the strategy outlined above, i.e. knockdown of ZEB1 in combination with TGF- $\beta$ treatment. Consistent with the Western blot data (Figure 5A), ZEB1 knockdown indeed antagonized the TGF- $\beta$-induced reduction of the cell-surface CAR levels measured by flow cytometry (Figure 7A). Analogously, silencing of ZEB1 in MDA-MB-231 cells increased cell surface CAR expression (Figure 7B).

In agreement with the total CAR protein (Figure 5A) and cell-surface CAR (Figure 7A) data, PANC-1 cells with silenced ZEB1 expression were more susceptible to infection with a green fluorescence protein (GFP)encoding adenovirus (Ad-GFP) [9] than the TGF- $\beta$ treated non-silencing controls. This effect was apparent both at the level of GFP signal intensity (Figure 7C) and virus copy number (Figure 7D). For both methods, cells were harvested twenty-four hours post infection and were either analyzed by flow cytometry (GFP signal) or by TaqMan PCR (copy number) using adenoviral DNA (extracted together with cellular genomic DNA) as template. This data indicates that knockdown of ZEB1 might be a suitable approach to improve cellular uptake of therapeutic adenoviruses.

\section{Discussion}

Up-regulation of CAR may be achieved by treatment with pharmacological inhibitors of RAS-MEK [5], of TGF- $\beta$ signaling [9], or with HDAC inhibitors [6,7]. Here, we have demonstrated that ZEB1 plays a prominent role in the TGF- $\beta$-induced down-regulation of CAR, and that knockdown of ZEB1 is sufficient to improve adenovirus uptake.

We have previously noticed similar expression patterns for CAR and E-cadherin, and thus hypothesized that the underlying regulatory mechanisms are related. Here, we have functionally defined the minimal human CAR promoter and have shown that it contains four orthologously conserved motifs: putative ETS and CRE elements, and two closely spaced E2 boxes. Particularly the latter elements caught our attention, since they were reported to interact with E2 box transcriptional repressors such as ZEB1 [25,33-36] and SIP1 [23,33,35,39] in the E-cadherin promoter. Furthermore, the genetic context of the E2 boxes in the CAR (Figure 1B) and E-cadherin [39] promoters is similar. Indeed, overexpressed ZEB1 repressed the activity of the -291/-1 CAR promoter, and bound to CAR promoter oligonucleotides and chromatin. It is of note that Pong et al. suggested that the functional CAR promoter is located between -585 and -400 [10]. However, since the latter study did not address the role of the E2 boxes and primarily focused on CAR upstream sequence mediating positive regulation of promoter activity, it does not contradict our findings. Indeed, we have shown that the $-681 /-1$ CAR upstream fragment, containing the proposed $-585 /-400$ promoter, is associated with high promoter activity (Figure $1 \mathrm{~A})$.

Our ZEB1 knockdown experiments provide evidence that ZEB1 is a physiological repressor of CAR expression in PANC-1 and MDA-MB-231 cells. However, even though knockdown of ZEB1 was sufficient to antagonize the TGF- $\beta$-induced down-regulation of CAR and E-cadherin (Figure 5A), we did not observe consistent changes of the ZEB1 protein levels in PANC-1 cells neither in total nor nuclear fractions as consequence of the TGF- $\beta$ stimulation (Figure 5A-C). Therefore, in our PANC-1 EMT model, TGF- $\beta$ may activate ZEB1 rather than up-regulate its expression. Underlying mechanisms have not been described yet but may include posttranslational modification of ZEB1 or physical binding to TGF- $\beta$ downstream effectors. For instance, TGF- $\beta$ may enhance ZEB1's repressor activity by up-regulating expression and/or activity of ZEB1-associated co- 
A

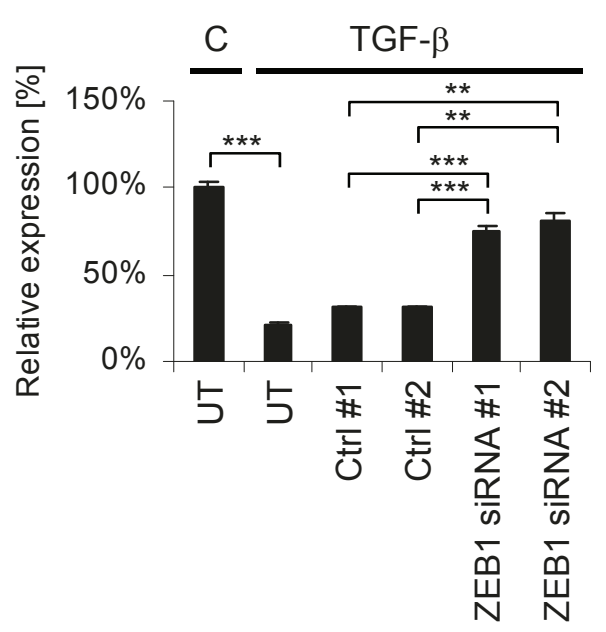

C

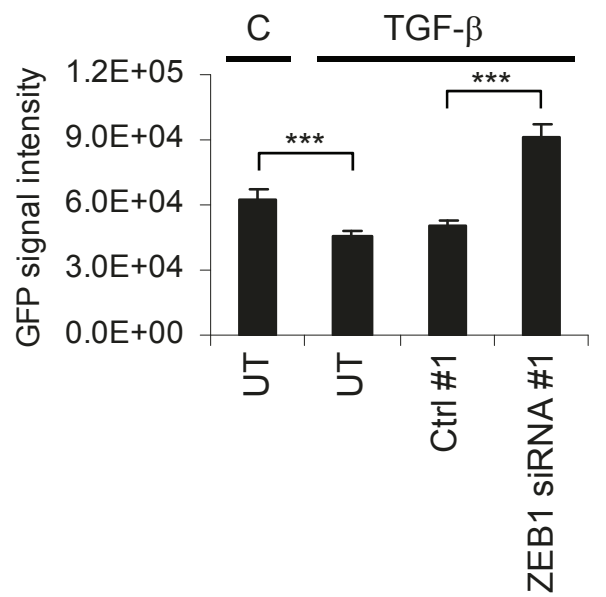

B

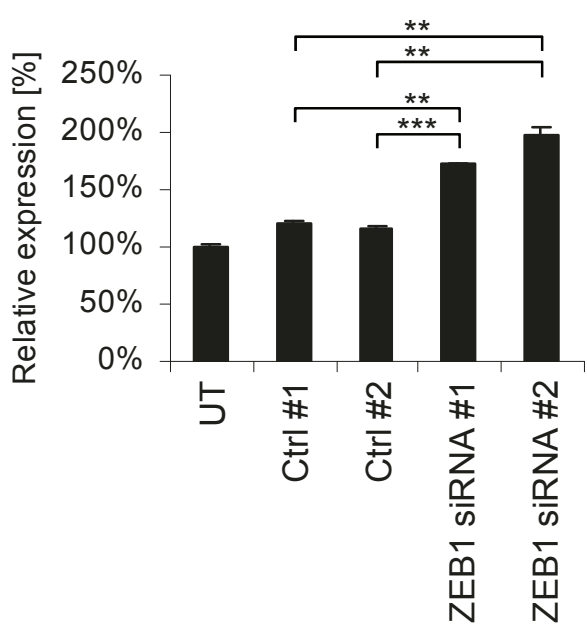

D

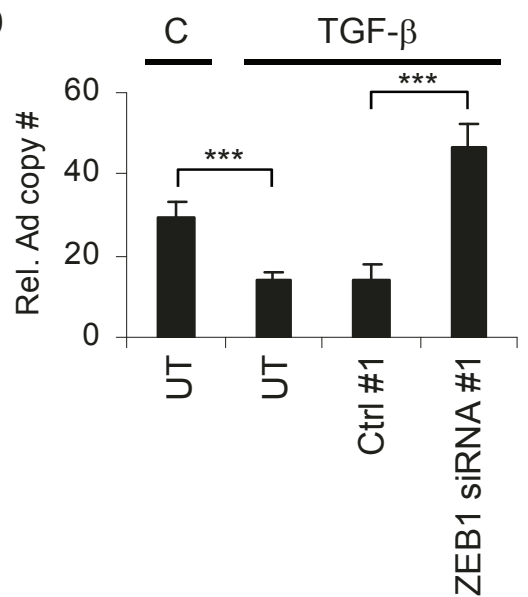

Figure 7 Up-regulation of cell-surface CAR levels upon ZEB1 knockdown coincides with increased adenoviral infectability. A and B Cell-surface CAR levels following ZEB1 knockdown were measured by flow cytometry on PANC-1 cells treated with TGF- $\beta 1$ (A), or on MDA-MB231 cells (B). Error bars represent standard deviations (biological duplicates). C and D. Ad-GFP uptake following ZEB1 knockdown was determined by flow cytometry measuring GFP levels (C), or by real-time PCR for virus copy number (D). Error bars represent standard deviations. A-D. CAR and GFP signals are expressed as geometric means of the fluorescence signal intensities normalized to the untreated controls (A-C), virus copy numbers as relative adenovirus fiber levels (D). Abbreviations: UT, untransfected; Ctrl \#1, siControl ON-TARGETplus Non-targeting siRNA \#1 (Dharmacon); Ctrl \#2, firefly luciferase-targeting siRNA; ZEB1 siRNA \#1/\#2, ZEB1-targeting siRNAs. Ctrl \#2 and ZEB1 siRNA sequences are provided in Additional file 1 (Table S3). $p<0.001$ ( $\left.\left.^{* * *}\right), p<0.01{ }^{(* *}\right)$ (Student's $t$-test, 1 -tailed, equal variance).

repressors such as CtBP-1/-2 and/or BRG1. In support, TGF- $\beta$ stimulation increased both $c t b p 1$ and $\operatorname{brg} 1$ mRNA levels in NMuMG cells ([53], supplementary table I), a murine cell line for which we and others reported a TGF- $\beta$-mediated down-regulation of CAR $[9,37]$. However, in contrast to our data obtained with (human) PANC-1 cells, NMuMG cells responded to TGF- $\beta$ stimulation with increased ZEB1 ( $\delta E F 1$ ) expression [35]. Nevertheless, BRG1 was shown to physically associate with ZEB1 to repress the E-cadherin promoter [54].

Even though ZEB1 is necessary for the TGF- $\beta$-induced inhibition of CAR expression, TGF- $\beta$ may activate factors other than co-repressors that physically interact with ZEB1 to down-regulate CAR. In such a model,
ZEB1 would play a role as a constitutive repressor of CAR and thereby counteract activating factors such as those interacting with the ETS and CRE elements (Figure 1). siRNA-mediated depletion of ZEB1 would ease repression and consequentially increase CAR levels. Such a model appears attractive (Figure 6): SnailSmad3/4 was shown to repress the mouse CAR promoter by a mechanism that involves interactions with E2 boxes and adjacent Smad-binding elements (SBEs) [37]. Intriguingly, similarly to the mouse CAR promoter, E2 box 2 in the human CAR promoter contains an adjacent SBE (5'-CAGA-3') as well (Figure 1B). This may indicate that the human CAR promoter can also potentially be inhibited by Snail-Smad3/4 [37]. Therefore, ZEB1 may regulate the basal CAR levels by mediating a certain 
degree of promoter inhibition when bound to E2 box 1. However, further repression through binding of SnailSmad3/4 to E2 box 2 may occur upon stimulation with TGF- $\beta$ (Figure 6). The assumption that the mesenchymal factor ZEB1 is bound to the CAR promoter even in the absence of TGF- $\beta$ may be regarded as a discrepancy to the epithelial features of PANC-1 cells (Figure 2, 3 and 5). However, even though these cells undergo TGF$\beta$-induced EMT, they may not be prototypical epithelial cells as they express some mesenchymal/stem cell markers and can be brought into a more typical epithelial state by inhibiting Cyr61 [55]. Furthermore, even though functional characterization of the role of Snail-Smad3/4 on the CAR promoter was conducted in mouse cells, in invasive human ductal breast carcinoma, nuclear expression of Snail, Smad3 and Smad4 correlated with loss of CAR expression at the invasive front [37]. This data is consistent with our model which postulates that SnailSmad3/4 may also negatively regulate the human CAR promoter (Figure 6).

Our work identifies ZEB1 as a negative regulator of cell-surface CAR expression and adenovirus uptake and thus as a candidate therapeutic target in treatment strategies with oncolytic adenoviruses. Responsive tumor types may include moderately to poorly differentiated gastrointestinal tumors with low CAR expression [4]. However, whether or not this approach is successful does not solely depend on how efficiently the virus is taken up by the respective target cells, but also how effectively it replicates once taken up. We and others recently demonstrated that $\mathrm{p} 21^{\mathrm{WAF} 1}$ acts as a negative regulator of adenovirus replication [7,11]. For instance, even though the HDAC inhibitor valproic acid (VPA) up-regulated CAR, and facilitated adenovirus uptake, it additionally increased $\mathrm{p} 21^{\text {WAF1 }}$ levels and reduced virus replication [7]. Therefore, if such a scenario also applies to approaches targeting ZEB1, it might be necessary to engineer a replication-competent adenovirus able to silence p21 expression to improve replication and cell killing.

In summary, we have shown that ZEB1 negatively regulates CAR expression and adenovirus uptake in the context of TGF- $\beta$-mediated EMT, and that inactivation of ZEB1 may induce some form and degree of MET. We have demonstrated that knockdown of ZEB1 antagonized the TGF- $\beta$-mediated EMT process and the down-regulation of CAR in PANC-1 cells.

\section{Conclusions}

Our findings may suggest that carcinoma cells in vivo, stimulated by stroma-derived TGF- $\beta$, might respond to ZEB1 inactivation with MET resulting in reduced invasiveness and CAR up-regulation, and in improved adenovirus uptake. The latter effect may translate into more effective therapies utilizing oncolytic adenoviruses.

\section{Additional material}

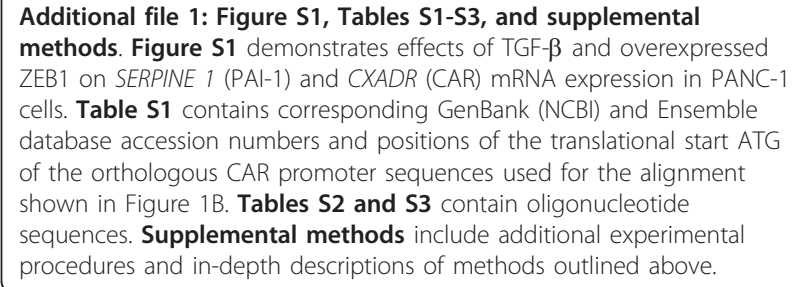

\section{Acknowledgements}

We are grateful to Drs. Tanja Tamgüney, David Dankort, Madhu Macrae and Walter Lacher for critical reading of the manuscript and suggestions, to Drs. Mike Fried, Stephan Gysin and Rosemary Akhurst for helpful discussions, and to Céline Sabatier Lacher for editing the manuscript. We are thankful to Dr. Kirsten Copren, Jennifer Dang, and Kathryn Thompson from the UCSF HDFCCC Genome Analysis Core, to Dr. Charles Nicolet and Heather Witt from the UC Davis Genome Center, and to Kristina Zumer for their excellent technical contribution. The pUHD10.3SIP1 construct is a generous gift from Dr. Frans van Roy. This work was supported by NIH grants R01 CA095701, R01 CA118545 (W.M.K), UCSF Discovery Grant 02-10242 (W.M.K), the Hellman Family Award (W.M.K), and the P30 CA82103 Cancer Center Support Grant.

\section{Author details}

${ }^{1}$ Dept. of Medicine, Division of Gastroenterology, University of California, San Francisco, CA, USA. ${ }^{2}$ Helen Diller Family Comprehensive Cancer Center, University of California, San Francisco, CA, USA. ${ }^{3}$ Current Address: BioTime, Inc., 1301 Harbor Bay Parkway, Suite 100, Alameda, 94502, CA, USA. ${ }^{4}$ Current Address: Cardiac Department National University Heart Centre Singapore, NUHS Tower Block, Level 9, 1 E Kent Ridge Road, Singapore, 119228, Republic of Singapore. ${ }^{5}$ Current Address: Swiss Institute for Experimental Cancer Research (ISREC), Swiss Federal Institute of Technology (EPFL) School of Life Sciences, Lausanne, 1015, Switzerland. ${ }^{6}$ Current Address: University of Hawaii Cancer Center, University of Hawaii, Honolulu, HI, USA. ${ }^{7}$ Dept. of Medicine, Division of Medical Oncology, University of California, San Francisco, CA, USA.

\section{Authors' contributions}

MDL designed and carried out experiments, and participated in the writing of the manuscript. MS conducted RNAi, adenoviral and immunofluorescence experiments. MIT performed RNAi and adenoviral experiments, PC was involved in construct generation and carrying out immunoblotting experiments. DK aligned orthologous CAR promoter sequences obtained from GenBank and Ensembl databases. WMK conceived and oversaw the project, and participated in the writing of the manuscript. All authors reviewed and approved the final manuscript.

\section{Competing interests}

The authors declare that they have no competing interests.

Received: 16 December 2010 Accepted: 27 July 2011

Published: 27 July 2011

\section{References}

1. Excoffon KJ, Gansemer ND, Mobily ME, Karp PH, Parekh KR, Zabner J: Isoform-specific regulation and localization of the coxsackie and adenovirus receptor in human airway epithelia. PloS one 2010, 5:e9909.

2. Lisewski U, Shi Y, Wrackmeyer U, Fischer R, Chen C, Schirdewan A, Juttner R, Rathjen F, Poller W, Radke MH, Gotthardt M: The tight junction protein CAR regulates cardiac conduction and cell-cell communication. The Journal of experimental medicine 2008, 205:2369-2379.

3. Bergelson JM, Cunningham JA, Droguett G, Kurt-Jones EA, Krithivas A, Hong JS, Horwitz MS, Crowell RL, Finberg RW: Isolation of a common 
receptor for Coxsackie B viruses and adenoviruses 2 and 5. Science 1997, 275:1320-1323.

4. Korn WM, Macal M, Christian C, Lacher MD, McMillan A, Rauen KA, Warren RS, Ferrell L: Expression of the coxsackievirus- and adenovirus receptor in gastrointestinal cancer correlates with tumor differentiation. Cancer Gene Ther 2006, 13:792-797.

5. Anders M, Christian C, McMahon M, McCormick F, Korn WM: Inhibition of the Raf/MEK/ERK pathway up-regulates expression of the coxsackievirus and adenovirus receptor in cancer cells. Cancer Res 2003, 63:2088-2095.

6. Goldsmith ME, Kitazono M, Fok P, Aikou T, Bates S, Fojo T: The histone deacetylase inhibitor FK228 preferentially enhances adenovirus transgene expression in malignant cells. Clin Cancer Res 2003, 9:5394-5401.

7. Hoti N, Chowdhury W, Hsieh JT, Sachs MD, Lupold SE, Rodriguez R: Valproic acid, a histone deacetylase inhibitor, is an antagonist for oncolytic adenoviral gene therapy. Mol Ther 2006, 14:768-778.

8. Kuster K, Koschel A, Rohwer N, Fischer A, Wiedenmann B, Anders M: Downregulation of the coxsackie and adenovirus receptor in cancer cells by hypoxia depends on HIF-1alpha. Cancer Gene Ther 2010, 17:141-146.

9. Lacher MD, Tiirikainen MI, Saunier EF, Christian C, Anders M, Oft M, Balmain A, Akhurst RJ, Korn WM: Transforming growth factor-beta receptor inhibition enhances adenoviral infectability of carcinoma cells via up-regulation of Coxsackie and Adenovirus Receptor in conjunction with reversal of epithelial-mesenchymal transition. Cancer Res 2006, 66:1648-1657.

10. Pong RC, Lai YJ, Chen H, Okegawa T, Frenkel E, Sagalowsky A, Hsieh JT: Epigenetic regulation of coxsackie and adenovirus receptor (CAR) gene promoter in urogenital cancer cells. Cancer Res 2003, 63:8680-8686.

11. Shiina M, Lacher MD, Christian C, Korn WM: RNA interference-mediated knockdown of p21(WAF1) enhances anti-tumor cell activity of oncolytic adenoviruses. Cancer Gene Ther 2009

12. Lacher MD, Korn WM, Akhurst RJ: Transforming Growth Factor-beta in Cancer Therapy. Volume II. Chapter 43. Reversal of EMT by Small-Molecule Inhibitors of TGF-beta Type I and II Receptors: Implications for Carcinoma Treatment Totowa, New Jersey: Humana Press; 2008.

13. Kang Y, Massague J: Epithelial-mesenchymal transitions: twist in development and metastasis. Cell 2004, 118:277-279.

14. Yang J, Mani SA, Donaher JL, Ramaswamy S, Itzykson RA, Come C, Savagner P, Gitelman I, Richardson A, Weinberg RA: Twist, a master regulator of morphogenesis, plays an essential role in tumor metastasis. Cell 2004, 117:927-939.

15. Jorda M, Olmeda D, Vinyals A, Valero E, Cubillo E, Llorens A, Cano A Fabra A: Upregulation of MMP-9 in MDCK epithelial cell line in response to expression of the Snail transcription factor. J Cell Sci 2005, 118:3371-3385.

16. Akhurst RJ, Balmain A: Genetic events and the role of TGF beta in epithelial tumour progression. J Pathol 1999, 187:82-90.

17. Cui W, Fowlis DJ, Bryson S, Duffie E, Ireland H, Balmain A, Akhurst RJ: TGFbeta1 inhibits the formation of benign skin tumors, but enhances progression to invasive spindle carcinomas in transgenic mice. Cell 1996, 86:531-542.

18. Haddow S, Fowlis DJ, Parkinson K, Akhurst RJ, Balmain A: Loss of growth control by TGF-beta occurs at a late stage of mouse skin carcinogenesis and is independent of ras gene activation. Oncogene 1991, 6:1465-1470.

19. Iyer $S$, Wang ZG, Akhtari M, Zhao W, Seth P: Targeting TGFbeta signaling for cancer therapy. Cancer Biol Ther 2005, 4:261-266.

20. Massague J: TGFbeta in Cancer. Cell 2008, 134:215-230.

21. Massague J, Gomis RR: The logic of TGFbeta signaling. FEBS Lett 2006, 580:2811-2820.

22. Siegel PM, Massague J: Cytostatic and apoptotic actions of TGF-beta in homeostasis and cancer. Nat Rev Cancer 2003, 3:807-821.

23. Vandewalle C, Comijn J, De Craene B, Vermassen P, Bruyneel E, Andersen H, Tulchinsky E, Van Roy F, Berx G: SIP1/ZEB2 induces EMT by repressing genes of different epithelial cell-cell junctions. Nucleic Acids Res 2005, 33:6566-6578

24. De Craene B, Gilbert B, Stove C, Bruyneel E, van Roy F, Berx G: The transcription factor snail induces tumor cell invasion through modulation of the epithelial cell differentiation program. Cancer Res 2005, 65:6237-6244.
25. Peinado H, Olmeda D, Cano A: Snail, Zeb and bHLH factors in tumour progression: an alliance against the epithelial phenotype? Nat Rev Cancer 2007, 7:415-428

26. Bracken CP, Gregory PA, Kolesnikoff N, Bert AG, Wang J, Shannon MF, Goodall GJ: A double-negative feedback loop between ZEB1-SIP1 and the microRNA-200 family regulates epithelial-mesenchymal transition. Cancer Res 2008, 68:7846-7854.

27. Burk U, Schubert J, Wellner U, Schmalhofer O, Vincan E, Spaderna S, Brabletz T: A reciprocal repression between ZEB1 and members of the miR-200 family promotes EMT and invasion in cancer cells. EMBO Rep 2008, 9:582-589.

28. Yu J, Ohuchida K, Mizumoto K, Sato N, Kayashima T, Fujita H, Nakata K, Tanaka M: MicroRNA, hsa-miR-200c, is an independent prognostic factor in pancreatic cancer and its upregulation inhibits pancreatic cancer invasion but increases cell proliferation. Mol Cancer 2010, 9:169.

29. Martin TA, Goyal A, Watkins G, Jiang WG: Expression of the transcription factors snail, slug, and twist and their clinical significance in human breast cancer. Ann Surg Oncol 2005, 12:488-496.

30. Rosivatz E, Becker I, Specht K, Fricke E, Luber B, Busch R, Hofler H, Becker KF: Differential expression of the epithelial-mesenchymal transition regulators snail, SIP1, and twist in gastric cancer. Am J Pathol 2002, 161:1881-1891.

31. Singh M, Spoelstra NS, Jean A, Howe E, Torkko KC, Clark HR, Darling DS, Shroyer KR, Horwitz KB, Broaddus RR, Richer JK: ZEB1 expression in type I vs type II endometrial cancers: a marker of aggressive disease. Mod Pathol 2008, 21:912-923.

32. Spoelstra NS, Manning NG, Higashi Y, Darling D, Singh M, Shroyer KR, Broaddus RR, Horwitz KB, Richer JK: The transcription factor ZEB1 is aberrantly expressed in aggressive uterine cancers. Cancer Res 2006, 66:3893-3902.

33. Remacle JE, Kraft H, Lerchner W, Wuytens G, Collart C, Verschueren K, Smith JC, Huylebroeck D: New mode of DNA binding of multi-zinc finger transcription factors: deltaEF1 family members bind with two hands to two target sites. Embo J 1999, 18:5073-5084.

34. Aigner K, Dampier B, Descovich L, Mikula M, Sultan A, Schreiber M, Mikulits W, Brabletz T, Strand D, Obrist $P$, et al: The transcription factor ZEB1 (deltaEF1) promotes tumour cell dedifferentiation by repressing master regulators of epithelial polarity. Oncogene 2007, 26:6979-6988.

35. Shirakihara T, Saitoh M, Miyazono K: Differential regulation of epithelial and mesenchymal markers by deltaEF1 proteins in epithelial mesenchymal transition induced by TGF-beta. Mol Biol Cell 2007, 18:3533-3544.

36. Grooteclaes ML, Frisch SM: Evidence for a function of CtBP in epithelial gene regulation and anoikis. Oncogene 2000, 19:3823-3828.

37. Vincent T, Neve EP, Johnson JR, Kukalev A, Rojo F, Albanell J, Pietras K, Virtanen I, Philipson L, Leopold PL, et al: A SNAIL1-SMAD3/4 transcriptional repressor complex promotes TGF-beta mediated epithelial-mesenchymal transition. Nat Cell Biol 2009, 11:943-950.

38. Thompson JD, Higgins DG, Gibson TJ: CLUSTAL W: improving the sensitivity of progressive multiple sequence alignment through sequence weighting, position-specific gap penalties and weight matrix choice. Nucleic Acids Res 1994, 22:4673-4680.

39. Comijn J, Berx G, Vermassen P, Verschueren K, van Grunsven L, Bruyneel E, Mareel M, Huylebroeck D, van Roy F: The two-handed E box binding zinc finger protein SIP1 downregulates E-cadherin and induces invasion. Mol Cell 2001, 7:1267-1278.

40. Matys V, Kel-Margoulis OV, Fricke E, Liebich I, Land S, Barre-Dirrie A, Reuter I, Chekmenev D, Krull M, Hornischer $K$, et al: TRANSFAC and its module TRANSCompel: transcriptional gene regulation in eukaryotes. Nucleic Acids Res 2006, 34:D108-110.

41. Benbrook DM, Jones NC: Different binding specificities and transactivation of variant CRE's by CREB complexes. Nucleic Acids Res 1994, 22:1463-1469.

42. Paca-Uccaralertkun S, Zhao LJ, Adya N, Cross JV, Cullen BR, Boros IM, Giam CZ: In vitro selection of DNA elements highly responsive to the human T-cell lymphotropic virus type I transcriptional activator, Tax. Mol Cell Biol 1994, 14:456-462.

43. Kim J, You L, Xu Z, Kuchenbecker K, Raz D, He B, Jablons D: Wnt inhibitory factor inhibits lung cancer cell growth. J Thorac Cardiovasc Surg 2007, 133:733-737. 
44. Ginzinger DG: Gene quantification using real-time quantitative PCR: an emerging technology hits the mainstream. Exp Hematol 2002, 30:503-512.

45. Hata A, Seoane J, Lagna G, Montalvo E, Hemmati-Brivanlou A, Massague J: OAZ uses distinct DNA- and protein-binding zinc fingers in separate BMP-Smad and Olf signaling pathways. Cell 2000, 100:229-240

46. Ginzinger DG, Godfrey TE, Nigro J, Moore DH, Suzuki S, Pallavicini MG, Gray JW, Jensen RH: Measurement of DNA copy number at microsatellite loci using quantitative PCR analysis. Cancer Res 2000, 60:5405-5409.

47. Bowles KR, Gibson J, Wu J, Shaffer LG, Towbin JA, Bowles NE: Genomic organization and chromosomal localization of the human Coxsackievirus B-adenovirus receptor gene. Hum Genet 1999, 105:354-359.

48. Buckland PR: The importance and identification of regulatory polymorphisms and their mechanisms of action. Biochim Biophys Acta 2006, 1762:17-28.

49. Quandt K, Frech K, Karas H, Wingender E, Werner T: Matind and MatInspector: new fast and versatile tools for detection of consensus matches in nucleotide sequence data. Nucleic acids research 1995, 23:4878-4884.

50. Ellenrieder V, Hendler SF, Boeck W, Seufferlein T, Menke A, Ruhland C, Adler G, Gress TM: Transforming growth factor beta1 treatment leads to an epithelial-mesenchymal transdifferentiation of pancreatic cancer cells requiring extracellular signal-regulated kinase 2 activation. Cancer Res 2001, 61:4222-4228.

51. Ui-Tei $K$, Naito $Y$, Nishi $K$, Juni A, Saigo K: Thermodynamic stability and Watson-Crick base pairing in the seed duplex are major determinants of the efficiency of the siRNA-based off-target effect. Nucleic acids research 2008, 36:7100-7109.

52. Bakin AV, Tomlinson AK, Bhowmick NA, Moses HL, Arteaga CL: Phosphatidylinositol 3-kinase function is required for transforming growth factor beta-mediated epithelial to mesenchymal transition and cell migration. J Biol Chem 2000, 275:36803-36810.

53. Xie L, Law BK, Aakre ME, Edgerton M, Shyr Y, Bhowmick NA, Moses HL: Transforming growth factor beta-regulated gene expression in a mouse mammary gland epithelial cell line. Breast Cancer Res 2003, 5:R187-198.

54. Sanchez-Tillo E, Lazaro A, Torrent R, Cuatrecasas M, Vaquero EC, Castells A, Engel P, Postigo A: ZEB1 represses E-cadherin and induces an EMT by recruiting the SWI/SNF chromatin-remodeling protein BRG1. Oncogene 2010, 29:3490-3500.

55. Haque I, Mehta S, Majumder M, Dhar K, De A, McGregor D, Van Veldhuizen PJ, Banerjee SK, Banerjee S: Cyr61/CCN1 signaling is critical for epithelial-mesenchymal transition and stemness and promotes pancreatic carcinogenesis. Molecular cancer 2011, 10:8.

56. Chen JW, Ghosh R, Finberg RW, Bergelson JM: Structure and chromosomal localization of the murine coxsackievirus and adenovirus receptor gene. DNA and cell biology 2003, 22:253-259.

doi:10.1186/1476-4598-10-91

Cite this article as: Lacher et al.: ZEB1 limits adenoviral infectability by transcriptionally repressing the Coxsackie virus and Adenovirus Receptor. Molecular Cancer 2011 10:91.

\section{Submit your next manuscript to BioMed Central and take full advantage of:}

- Convenient online submission

- Thorough peer review

- No space constraints or color figure charges

- Immediate publication on acceptance

- Inclusion in PubMed, CAS, Scopus and Google Scholar

- Research which is freely available for redistribution

Submit your manuscript at www.biomedcentral.com/submit
Biomed Central 